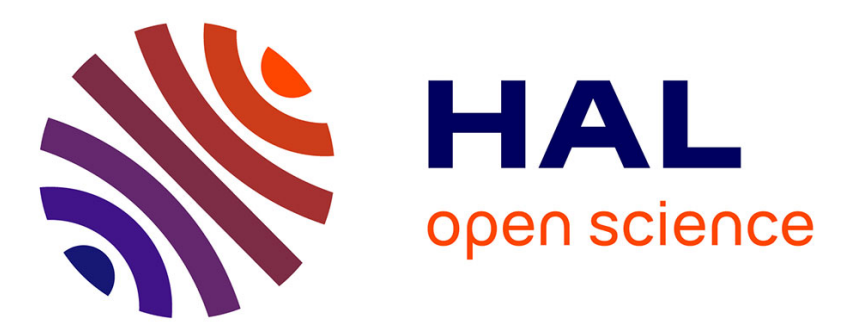

\title{
Research on Fault Analysis and Fault-Tolerant Control of EV/HEV Powertrain
}

Bekheira Tabbache, Abdelaziz Kheloui, Mohamed Benbouzid, Abdeslam

Mamoune, Demba Diallo

\section{- To cite this version:}

Bekheira Tabbache, Abdelaziz Kheloui, Mohamed Benbouzid, Abdeslam Mamoune, Demba Diallo. Research on Fault Analysis and Fault-Tolerant Control of EV/HEV Powertrain. IEEE ICGE 2014, Mar 2014, Sfax, Tunisia. pp.284-289. hal-01023503

\section{HAL Id: hal-01023503 https://hal.science/hal-01023503}

Submitted on 24 Jul 2014

HAL is a multi-disciplinary open access archive for the deposit and dissemination of scientific research documents, whether they are published or not. The documents may come from teaching and research institutions in France or abroad, or from public or private research centers.
L'archive ouverte pluridisciplinaire HAL, est destinée au dépôt et à la diffusion de documents scientifiques de niveau recherche, publiés ou non, émanant des établissements d'enseignement et de recherche français ou étrangers, des laboratoires publics ou privés. 


\section{Research on Fault Analysis and Fault-Tolerant Control of EV/HEV Powertrain}

\author{
B. Tabbache, A. Kheloui \\ Ecole Militaire Polytechnique, \\ Algiers, Algeria \\ laid_tabache@yahoo.com
}

\author{
M.E.H. Benbouzid, A. Mamoune \\ University of Brest, EA 4325 LBMS \\ Brest, France \\ Mohamed.Benbouzid@univ-brest.fr
}

\author{
D. Diallo \\ University of Paris XI \\ Gif-Sur-Yvette 91192, France \\ ddiallo@ieee.org
}

\begin{abstract}
This paper presents research works in the topics of fault analysis and fault tolerant control of an electric vehicle powered by an inverter-fed induction motor drive and the usual sensors. The considered failures are mainly measurement error due to faulty sensors and power inverter malfunctions. When sensor failure occurs, both software and hardware redundancies have been investigated. Software redundancy has been evaluated in case of speed sensor failure. Hardware redundancy has been used in the case of power inverter failures with a fault-tolerant 4-leg topology. This topology exploits the induction motor neutral accessibility for fault-tolerant purposes. The proposed fault-tolerant approach brings a significant improvement compared to the phase-leg topology. This paper also presents the experimental validation of an efficient reconfiguration mechanism (transition strategy) at sensor fault occurrence.
\end{abstract}

Index Terms-Electric vehicle, induction motor, inverter, fault-tolerant control, IGBT failure, hysteresis control, 3D SVPWM.

\section{INTRODUCTION}

Performance, efficiency, availability, reliability and safety are beside productivity, the main requirements in many industrial systems. To achieve these goals, monitoring and supervision are embedded in the electrical energy conversion chain. A monitoring task allows characterizing the operation mode, recording information, recognizing and indicating abnormalities. Supervision functions indicate the undesirable or not permitted states of the process, and take appropriate actions to maintain good behavior and avoid damage or accidents. Indeed, this is known as Fault-Tolerant Control (FTC) that is designed to detect, diagnose and isolate the faults and engage the appropriate control strategy to maintain the system operation.

Initially, FTC has been implemented in sensible applications such as aerospace, nuclear power, automotive, manufacturing and other process industries [1-3-38-39-40]. As a result, a significant amount of research on FTC systems was motivated by aircraft flight control system designs [4]. Moreover, in safety-critical nuclear power industries, interests in diagnostics and fault-tolerant control of nuclear power plants have been intensified [5].

Fault tolerance is no longer limited to high-end systems, but also to railway [6] and automobile applications [7]. It is gaining growing interest to increase the reliability and the continuous operation of electromechanical systems [3-8] Indeed, extensive researches have been conducted towards fault-tolerant AC motor drives in industrial applications [9-1041].

\section{ELECTRIC VEHICLE POWERTRAIN COMPONENTS AND FAILURES}

The electric propulsion system is the main component of an electric vehicle [11-12]. It's composed mainly of (Fig. 1): an embedded energy source, energy Converters, a mechanical or electrical differential, a mechanical transmission and a control unit.

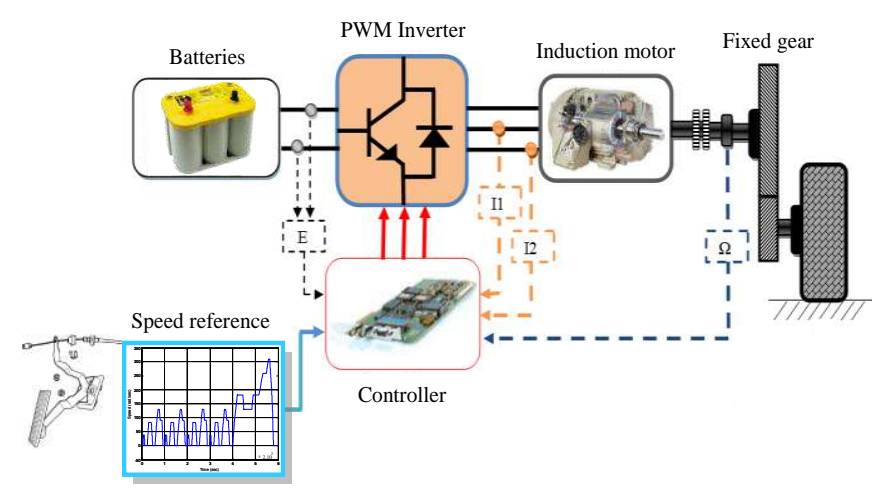

Fig 1. Electric vehicle powertrain

Faults or failures can affect all the components of the system: motors, power converters, sensors or wires and connectors.

\section{A. Electrical motor failures}

The electrical motor is the principal element of the electric propulsion system. Manufacturers of electric vehicles use DC or AC motor such as induction motor (IM), permanent magnet synchronous motor (PMSM) and switched reluctance motor (SRM) [13-14].

The failures in the electric motor can have various origins: 
- Failures related to wrong design and/or weak dimensioning which lead to a premature degradation,

- Failures related to the exploitation (frequent overloads, violent transients or severe environment) that can lead to faults and also a premature degradation.

In AC motors, faults can be located in the stator or the rotor [15-16]. In the stator, the main faults (Fig. 2) concern the windings such as insulation fault, winding turn-to-turn short circuit, winding-to-ground fault and phase-to-phase short circuit [42-43].

In the rotor, the failures concern the magnetic circuit or the mechanical parts such as bearings [17-44].

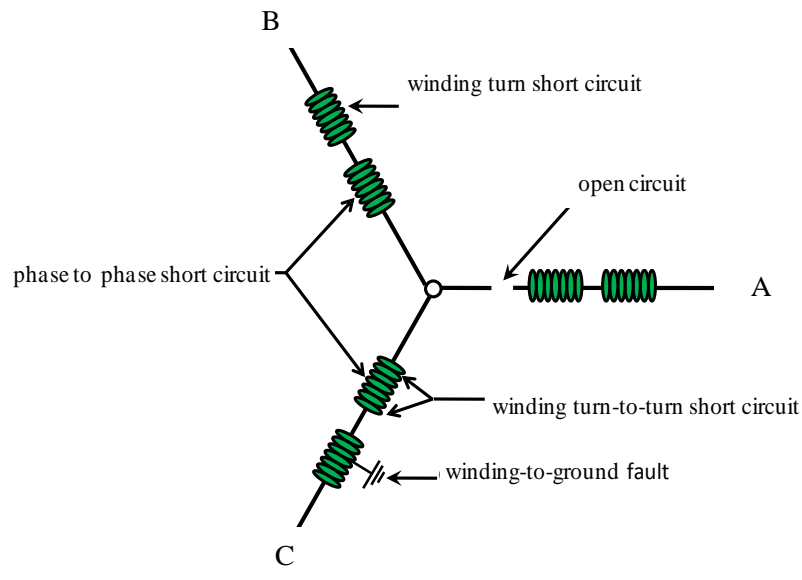

Fig.2 Failures in induction motor stator

\section{B. Sensors failures}

A sensor is a device transforming the state of a physical quantity observed into a usable quantity. In electric motor control two types of sensors are used:

- Current and voltage sensors

- Position or speed sensors

The performance of the system can be measured by the health of the sensors used in the process control. Sensor faults can be partial or total. In case of total failure such as the loss of contact with the ground or a cut of an electric wire, the sensor gives no information or an information which does not correspond to the true value of the measured variable. In case of partial failure, the sensor delivers a signal at least adequate to the true value of the measured variable.

In this study, two types of sensors are treated: speed and current sensors.

1) Speed and position sensor failures : The main position and speed sensors used in industry are [18]: tachometer generator, incremental encoder, and absolute encoder.

The most used in industry are incremental and absolute encoders. The position measurement range and resolution depend on the number $\mathrm{N}$ of bits.

The main advantage of the absolute encoder is that it provides the absolute position information, while the incremental encoder gives a relative position (relative to an initial position). When the power supply is subject to cuts or when the transmission is sensitive to noise, an absolute encoder is recommended.

In general the encoder can exhibit the following failure conditions:

- Intermittent sensor connection,

- Complete sensor outage,

- DC bias in sensor measurement, and

- Sensor gain drop.

The most severe failures are the first two ones as they lead to momentary or complete lack of information. This will obviously lead to instabilities in closed-loop control if no remedial actions are undertaken [19]-[20].

The origin of these failures can be also mechanical (slipping between the sensor and the rotor axle) and electrical (the cut of the power supply of the sensor, failure of the conditioning part of the signal). All these failures can be significant factors to destabilize the motor control.

The mathematical representation of a speed sensor (encoder) can be given by [21]:

$$
\omega_{m}^{m}=(1-\gamma) \cdot \omega_{m} \quad 0 \leq \gamma \leq 1
$$

$\omega_{m}^{m}:$ the measured mechanical speed of the motor. $m$ indicates the measured or estimated values.

In control system, speed varies according to the amplitude of encoder failure. If $\gamma=1$, the control generates a positive torque which leads to destabilization.

If $\mathrm{O}<\gamma<1$, the motor speed does not follow the reference speed and it increases with a value of $(1+\gamma) \omega_{\text {ref }}$.

2) Current and voltage sensor failures: In general, the current sensors used by the control are Hall Effect type.

The main faults of the current sensor are: Gain variation, Offset, Saturation, Noise, Open- circuit and intermittent disconnection of circuit [21-45].

An offset failure can produce torque ripples at a frequency equal to the power supply frequency

A gain variation in the current sensor produces a torque ripple at twice the supply frequency.

\section{Power inverter failures}

In electric vehicle powertrain, three converters are envisaged: AC-DC converter (Rectifier), DC-DC converter (Chopper), and DC-AC converter (Inverter).

In industry, AC motors are usually fed with 2-level inverter built with six bidirectional power switches (IGBT or MOSFET)

Figure 3 summarizes potential faults that could afflict a power inverter. Two common types of power converter faults 
that were investigated are transistor gate-drive open fault or IGBT open-circuit switch fault $\left(\mathrm{F}_{3}\right)$, and IGBT short-circuit switch fault $\left(\mathrm{F}_{4}\right)$, as depicted in Fig. 3. These two faults can lead to catastrophic failures of the drive or to significantly degraded performances. It is therefore crucial to detect and diagnose these two faults so as to take the appropriate remedial action to mitigate the fault effects [22-23].

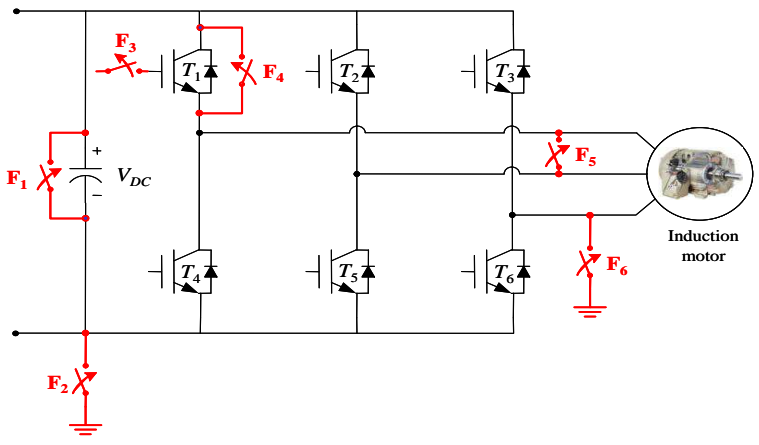

Fig. 3. Potential inverter faults.

It is estimated that about $38 \%$ of the faults in variablespeed ac drives in industry are due to failures of power devices [22], [24-25]. This percentage will be higher if control circuit failures are taken into account. They may consist of faults such as inverter intermittent misfiring due to defects in control circuit elements or electromagnetic interference that results in gate-drive open faults, and consequently leads to IGBT open-circuit.

Although IGBTs are rugged, they suffer failures due to excess electrical and thermal stress that are experienced in harsh environments such in automotive applications. IGBT failures can be broadly categorized as open-circuit faults, short-circuit faults, and intermittent gate-misfiring faults [22].

1) Open-circuit Failure: These faults can be provided by the failure of the grid. They produce a loss of the current reversibility in the power transistor. In this case, the induction motor currents lose negative or positive alternation and therefore became non sinusoidal.

The high ripples in the speed and torque can lead to mechanic vibration and therefore reduce the lifetime of these components [46].

2) Short-circuit failure: These failures are more critical because the commutation cell of the power inverter can be definitively short-circuited [19]. In this case, the induction motor currents have high values. Only the internal resistance of the circuit formed of the commutation cells and the induction motor limits these values. The current of shortcircuit can reach excessive amplitudes in a short time.

The motor currents provide a strongly oscillating torque with an average value that can lead to rotor breakage.

\section{FAULT-TOLERANT CONTROL OF EV POWERTRAIN}

In event of failure, repetitive and frequent maintenance is rarely a solution approved by manufacturers. The system is usually turned off during maintenance, and cannot produce to satisfy the growing demands. For this, many researches are developed to find solutions to ensure the availability of the system. These solutions deal with the development of algorithms and techniques ensuring the continuity of the operation system in the case of failures. They called: Fault tolerant control [47].

Fault Tolerant Control (FTC) approaches are divided into two classes: passive and active approaches. Passive methods are based on robust control techniques. Active approaches are generally divided into subclasses: Faults Accommodation and system Reconfiguration.

\section{A. EV Electric Drive Active Fault-Tolerant Control}

An active fault-tolerant approach, as illustrated by Fig.4, has been adopted. To achieve this goal, a reorganizing controller will adopt the best control methodology depending on the available feedback and operational hardware [8]. This controller comprises two parts: failure detection and fallback strategy. While the first part monitors the status of the sensors, the second one will engage the appropriate control strategy according to the fault severity [7].

\section{B. Redundancy And The Key of EV AFTC!}

Redundancy is the key in any fault-tolerant system. Redundancy can be categorized into two types; direct (hardware) and analytical (software).

In the event of material failures, the use of software and hardware redundancies can be an effective approach to increase the system reliability. The reconfiguration system based on these components need a management or voting algorithm in order to choose between the inputs (software or hardware versions), the correct output of the system.

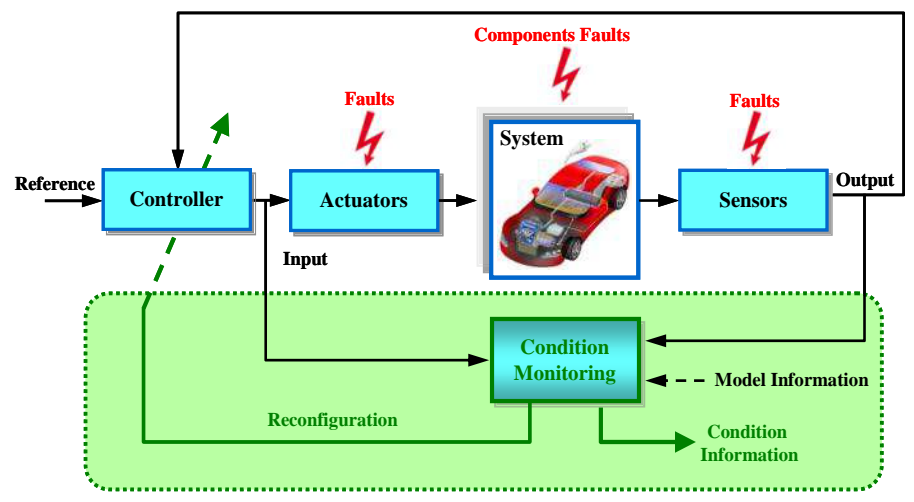

Fig.4 Active fault-tolerant control scheme

The voting algorithms are used to ensure the safety and security. They use hardware and software inputs (versions) to select the best input [26]. 
1) Hardware redundancy : It's called also direct redundancy. It consists in associating additional components in parallel with the main components. As an example, two or three sensors that measure the same quantity can be used. In normal operation, only one sensor is sufficient, however, two or three sensors are required to ensure reliable measurements in case of faults. The hardware redundancy concept can also be extended to the actuators.

In the case of sensors fault, figure 5 describes the faulttolerant control scheme based on the hardware redundancy. In this context, in [36], three current and voltage sensors are used to ensure tolerance in event of faults as

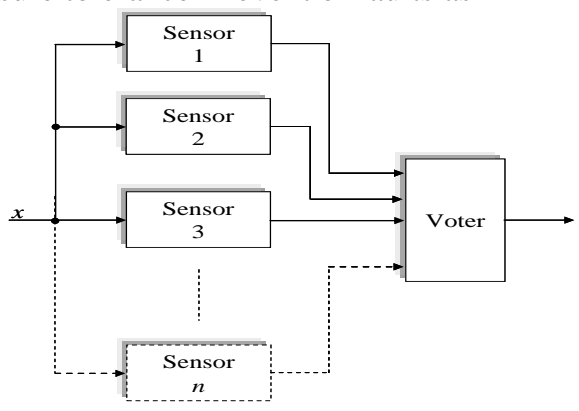

Fig.5 Hardware redundancy

The proposed sensor fault detection and post fault-tolerant control approach is evaluated for an electric vehicle using a $37-\mathrm{kW}$ induction motor based powertrain. Simulations are carried-out using a European urban and extra urban driving cycle (ECE + URL) as speed reference. For that purpose, two sensor faults are introduced: a current sensor fault in phase a (an offset) at 2-sec and a speed sensor fault (a signal disconnection) at 7-sec (Fig. 9).

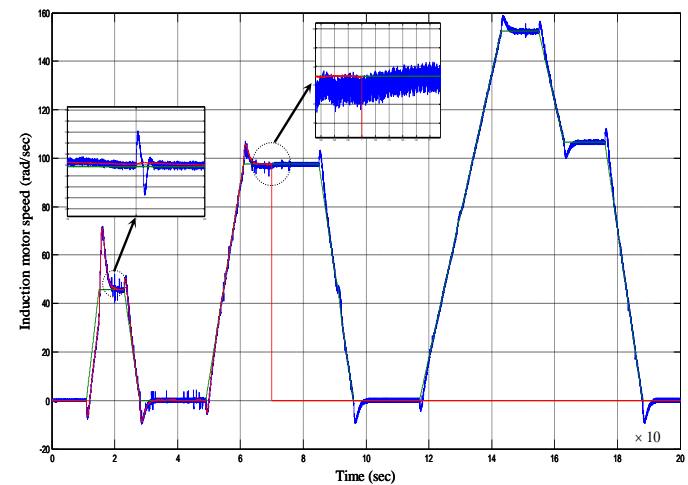

Fig. 6. EV FTC performances: Measured speed (red), estimated speed (blue) and reference speed (green)

In case of inverter faults, 4-Leg Inverter Fault-Tolerant Control is presented in many works [37-48-49].

Fault tolerance for an induction motor drive can be accomplished by adding an extra inverter leg to a standard three-phase voltage source inverter configuration [28-31]. The extra leg is connected to the induction motor neutral point that requires a star-connected machine with an available neutral. The considered fault-tolerant inverter configuration considered is shown in Fig.7.

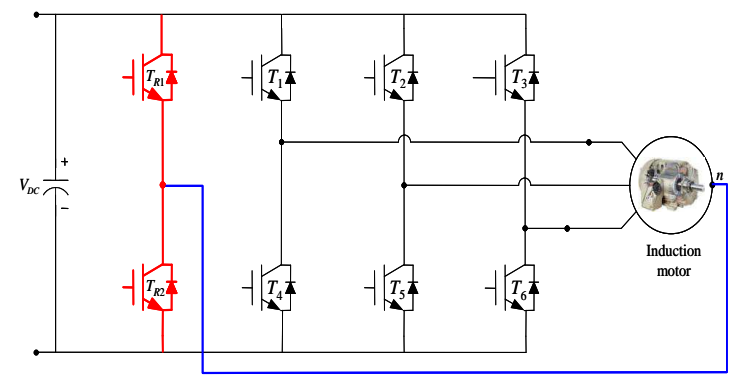

Fig. 7. 4-leg inverter neutral-connected induction motor fault-tolerant topology.

This new control structure will consist in modifying the control references taking into account the induction motor neutral current.

In embedded applications where mass and cost are critical issues, hardware redundancy is no longer acceptable. This motivated the development of the concept of "analytical redundancy" [27].

2) Software (analytical) redundancy: In this case, there is no additional hardware implemented. Their virtual counterparts built with mathematical models such as observers replace the components. For example, instead of having multiple sensors that measure the same signal, an observer that gives an estimate of the signals provides analytical redundancy. Because the analytical redundancy eliminates the requirements for extra hardware, weight and cost of the FDI system are significantly reduced. This is very useful in the case of critical systems such as satellites and spacecraft applications where energy saving and weight reduction are mandatory.

However, there are still challenging issues for AFTCS design regarding [32]:

- The overall fault-tolerant and redundant system architecture;

- Optimal configuration of hardware and software redundancy by trading off reliability specifications against the cost;

- How to design and implement a fault-tolerant controller to best utilize both types of redundancies in order to achieve design objectives,

- Stability assessment.

In the case of Software (analytical) redundancy, and in the proposed speed sensor FTC approach, the extended Kalman filter and the Luenberger observer (adaptive one) are adopted as speed observers. Indeed, they will be used to determine the induction motor speed and generate the residuals used by the voting algorithm.

Figure 8 describes the software redundancy principle used in this section.

For example, the FTC approach in [35] and in case of encoder failures, the proposed strategy reorganizes itself using the estimated speed given by the voting algorithm in the 
entire speed range. Adopting a normal European urban driving cycle, Fig. 9 shows the FTC dynamic performances. In this case, the voting algorithm adopts the speed sensor output; at low speed it adopts the extended Kalman filter estimates (in case of failure); and at high speed it adopts the Luenberger observer estimates (in case of failure).

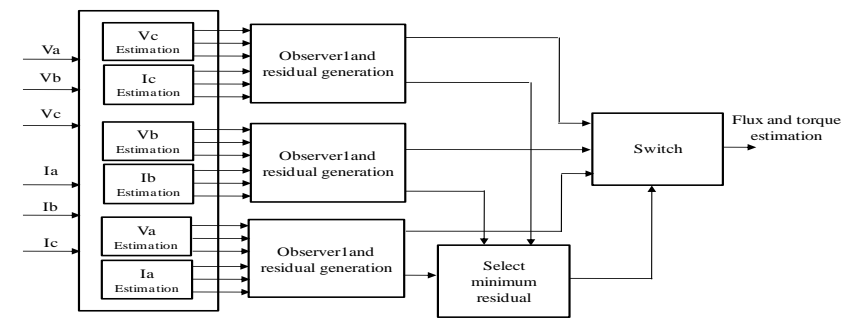

Fig.8. Software redundancy.

\section{TRANSIENT/TRANSITION TECHNIQUES}

In FTCS, undesirable transients may occur during the controller reconfiguration process. The consequences of these transients may cause saturations in actuators, and worse, damage to components in the system. Therefore, such transients should be minimized as much as possible. However, how to manage or reduce these transients during a controller reconfiguration is still an open issue. Very few results are available in the literature, although several works have been done. The potential solutions in reducing reconfiguration transients may lie in how to manage the system/controller states or control inputs [33].

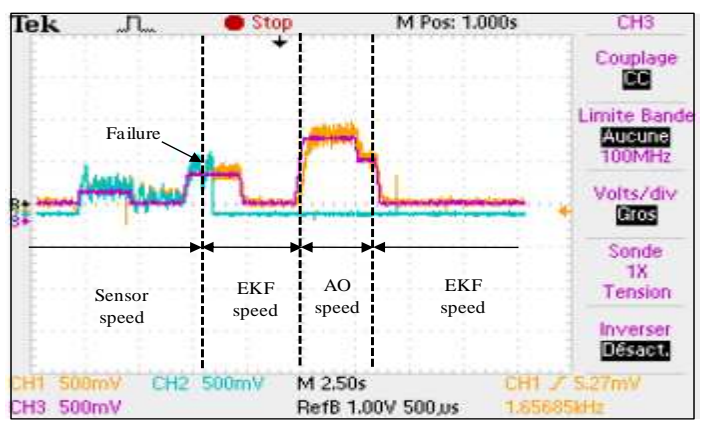

(Motor speed (orange), Encoder (blue), Reference speed (Purple))

Fig. 9. Induction motor drive MLV-based FTC performances under speed sensor failures

In [34], the smooth transition is obtained when the phaseshift between the controllers is zero or very close to zero. However, this case cannot be realized in all operation time. Therefore, forcing the synchronization of the both controllers is promising solution. The synchronization means that the both control voltage have the same control angle. It based on the initialization of the PI controller of the second control technique [34].

\section{V.SUMMARY AND CONCLUSIONS}

This paper presents research works in fault and fault tolerant control of electric vehicle powertrains mainly composed of an induction motor, a 2-level PWM inverter and an instrument chain. The considered failures were mainly measurement error due to faulty sensors and power inverter malfunctions.

In event of sensors failures, both software and hardware redundancies have been used. For software redundancy, this paper has presented a fault-tolerant direct torque control strategy in case of speed sensor failure intended for EVs using induction motor-based powertrain. For that purpose, it has been used the voting algorithm in the control decision block that computes the most accurate speed information from the speed sensor and two virtual sensors (extended Kalman filter and a Luenberger observer).

For hardware redundancy, this paper describes faulttolerant control of an induction motor-based EV experiencing sensor faults (current, voltage, and speed). In the case of power inverter failures, inverter fault-tolerant topology has been presented: 4-leg inverter topology. This topology exploits the induction motor neutral accessibility for faulttolerant purposes. The 4-leg inverter topology has been adopted as a key candidate where the redundant leg is connected to the motor neutral.

Otherwise, this paper dealt with the experimental validation of a reconfiguration mechanism (transition strategy) for sensor fault-tolerant control in induction motorbased EVs. The reconfiguration strategy, whose main objective is to ensure short and smooth transients when switching from a controller using a healthy sensor to another sensorless controller in case of a sensor failure, consisted in forcing synchronization between the controllers' voltages by compensating for their phase difference at the switchover instant.

\section{REFERENCES}

[1] Bruccoleri, M., Amico, M.,and Perrone, G., "Distributed intelligent control of exceptions in reconfigurable manufacturing systems," International Journal of Production Research, 41(7), pp. 1393-1412, 2003.

[2] Mehrabi, M. G., Ulsoy, A. G., Koren, Y., and Heytler, P, "Trends and perspectives in flexible and reconfigurable manufacturing systems," Journal of Intelligent Manufacturing, 13(2), pp. 23-44,2002.

[3] M. Muenchhof, M. Beck and R. Isermann, "Fault-tolerant actuators and drives-Structures, fault detection principles and applications," Annual Reviews in Control, vol.33, n², pp. 136-148, December 2009.

[4] Steinberg, M, "Historical overview of research in reconfigurable flight control," Proceedings of IMechE, Part G: Journal of Aerospace Engineering, 219, pp. 263-275,2005.

[5] Y. Zhang et al., "Bibliographical review on reconfigurable fault tolerant control system", In Proceedings of the 5th Symposium on Fault Detection, Supervision and Safety for Technical Processes (SAFEPROCESS'2003). Washington D.C., USA, pp. 265-276. 2003.

[6] Bennett S.M. et al, "Sensor fault-tolerant control of a rail traction drive, Control Engineering Practice, vol. 7, n² 2, pp. 217-225, February 1999.

[7] D. Diallo et $a l$, "'A Fault-Tolerant Control Architecture for Induction Motor Drives in Automotive Applications" IEEE Transaction on vehicular technology,Vol.53,No.6 November 2004

[8] M.E.H. Benbouzid, D. Diallo and M. Zeraoulia, "Advanced faulttolerant control of induction-motor drives for EV/HEV traction applications: From conventional to modern and intelligent control techniques," IEEE Trans. Vehicular Technology, vol. 56, n², pp. 519 528, March 2007.

[9] A. Sayed-Ahmed, B. Mirafzal, and N.A.O. Demerdash, "Fault-tolerant technique for $\Delta$-connected AC-motor drives," IEEE Trans. Energy Conversion, vol. 26, n², pp. 646-653, June 2011. 
[10] Rothenhagen K. et al.: Current sensor fault detection, isolation, and reconfiguration for doubly fed induction generators, IEEE Trans. Industrial Electronics, vol. 56, $\mathrm{n}^{\circ} 10$, pp. 4239-4245, October 2009.

[11] C.C. Chan, "The state of the art of electric and hybrid vehicles," Proceedings of the IEEE, vol. 90, n², pp. 247-275, February 2002.

[12] C.C. Chan et al "Electric, hybrid, and fuel-cell vehicles: Architectures and modeling," IEEE Trans. Vehicular Technology, vol. 59, n², pp. 589-598, February 2010.

[13] M. Zeraoulia et al, "Electric motor drive selection issues for HEV propulsion systems: A comparative study" IEEE Trans. Vehicular Technology, vol. 55, n6, pp. 1756-1764, November 2006.

[14] G. Nanda et $a l$ "A Survey and Comparaison of Characteristics of Motor Drives used in Electric Vehicles", Electrical and Computer Engineering Canadian Conference, pp. 811-914, May 2006.

[15] A.H. Bonnett et $a l$ "Cause and Analysis of Stator and Rotor Failures in Three-Phase Squirrel-Cage Induction Motors", IEEE Transactions on Industry Applications, 1992, Vol. 28, n4, pp. 921-937.

[16] D. Birolleau, "Etude d'Actionneurs Electriques pour la Tolérance aux Fautes", PHD Thesis, L'Institut polytechnique de Grenoble, 2008.

[17] M. E. H. Benbouzid, "A Review of Induction Motors Signature Analysis as a Medium for Faults Detection" IEEE Transactions on Industrial Electronics, , Vol.47, no. 5, 2000, pp. 984-993.

[18] http://sitelec.org/cours/abati/captvit.ht.

[19] D.U. Campos-Delgado et al., "Fault-tolerant control in variable speed drives: a survey," IET Electric Power Applications, vol.2, n², pp. 121 134, March 2008.

[20] A. Akrad et al, "An Observer Based Mechanical Sensor Failure Fault Tolerant Controller Structure in PMSM drive, "IEEE International Electric Machines and Drives Conference IEMDC, Miami, USA 3-6 May 2009, pp. 669-674.

[21] K.S. Lee et $a l$., "Instrument fault detection and compensation scheme for direct torque controlled induction motor drives," IEE Proc. Control Theory \& Applications, vol. 150, n4, pp. 376-382, July 2003.

[22] B. Lu and S.K. Sharma, "A literature review of IGBT fault diagnostic and protection methods for power inverters," IEEE Trans. Industry Applications, vol. 45, $\mathrm{n}^{\circ}$ 5, pp. 1770-1777, September/October 2009.

[23] M.E.H. Benbouzid, C. Delpha, Z. Khatir, S. Lefebvre and D. Diallo, Faults Detection and Diagnosis in a Static Converter, Electrica Machines Diagnosis, Chap. 9, p. 271-316, ISBN: 978-1-84821-263-3, Wiley, ISTE, Paris 2011.

[24] R.R. Errabelli and P. Mutschler, "Fault-tolerant voltage source inverter for permanent magnet drives," IEEE Trans. Power Electronics, vol. 27, n 2 , pp. 500-508, February 2012.

[25] C.C. Yeh and N.A.O., "Induction motor-drive systems with fault tolerant inverter-motor capabilities," in Proceedings of the 2007 IEEE IEMDC, Antalya (Turkey), vol. 2, pp. 1451-1458, May 2007.

[26] Y. Leung, "Maximum likelihood voting for fault-tolerant software with finite output-space," IEEE Trans. Reliability, vol. 14, n³, pp. 419-427, September 1995.

[27] H. Y. Chung et al., "Development of a combined algorithm of on-line instrument failure detection with an improved generalized likelihood ratio method and suboptimal control on a PWR pressurizer". Nuclear Technology, 74, 113-131. (1986)

[28] S. Bolognani, M. Zordan, and M. Zigliotto, "Experimental fault-tolerant control of a PMSM drive," IEEE Trans. Industrial Electronics, vol. 47, n ${ }^{\circ}$, pp. 1134-1141, October 2000.

[29] W. Sae-Kok, D.M. Grant and B.W. Williams, "System reconfiguration under open-switch faults in a doubly fed induction machine," IET Renewable Power Generation, vol. 4, n5, pp. 458-470, September 2010.

[30] R.L. de Araujo Ribeiro, C.B. Jacobina, E.R.C. da Silva and A.M.N Lima, "Fault-tolerant voltage-fed PWM inverter AC motor drive systems," IEEE Trans. Industrial Electronics, vol. 51, n², pp. 439-446, April 2004.

[31] C.B. Jacobina, R.L. de Araujo Ribeiro, A.M.N. Lima and E.R.C. da Silva, "Fault-tolerant reversible AC motor drive system," IEEE Trans. Industry Applications, vol. 39, n², pp. 1077-1084, July/August 2003.

[32] S.Osder, "Practical view of redundancy management application and theory", Journal of Guidance, Control, and Dynamics, 22(1), 12-21. (1999).
[33] M.Guler et al, "Transition management for reconfigurable hybrid control systems", IEEE Control Systems Magazine, 23(1), 36-49. (2003).

[34] B. Tabbache, N. Rizoug, M.E.H. Benbouzid, A. Kheloui "A Control Reconfiguration Strategy for Post-Sensor FTC in Induction MotorBased Evs ," IEEE Transactions on Vehicular Technology, vol.62, n³ pp.965 - 971, March 2013.

[35] B. Tabbache, M.E.H. Benbouzid, A. Kheloui and J.M. Bourgeot "Virtual Sensor-Based Maximum Likelihood Voting Approach for Fault-Tolerant Control of Electric Vehicle Powertrains", IEEE Transactions on Vehicular Technology, vol.62, n³ , pp. 1075 - 1083 , March 2013.

[36] B. Tabbache, M.E.H. Benbouzid, A. Kheloui and J.M. Bourgeot "DSP Based Sensor Fault Detection and Post Fault-Tolerant Control of an InductionMotor-Based Electric Vehicle" International Journal of Vehicular Technology, Volume 2012, Article ID 608381, 7 pages , doi:10.1155/2012/608381, November 2012

[37] X. Li, Z. Deng, Z. Chen and Q. Fei, "Analysis and simplification of three-dimensional space vector PWM for three-phase four-leg inverters," IEEE Trans. Industrial Electronics, vol. 58, n², pp. 450 464, February 2011.

[38] Liu Xiuzhi ; Dai Yaping, "Summary of the research on the fault-tolerant control for networked control systems," 201325 th Chinese Control and Decision Conference (CCDC), 25-27 May 2013, pp: 3956 - 3961

[39] Bin Yu ; Youmin Zhang ; Jianguo Yan ; Yaohong Qu ; Zhuang Liu, "Fault tolerant control using linear quadratic technique against actuator faults in a UAV," 2013 32nd Chinese Control Conference (CCC), 26-28 July 2013, pp: 6294 - 6299

[40] Bing Sun ; Daqi Zhu ; Lingyan Sun, "A tracking control method with thruster fault tolerant control for unmanned underwater vehicles," 2013 25th Chinese Control and Decision Conference (CCDC), 25-27 May 2013 , pp: 3956 - 3961.

[41] Boukhnifer, M. ; Raisemche, A. ; Diallo, D., "Fault tolerant control design of induction motor drive in electrical vehicle: A hybrid control approach," 2013 21st Mediterranean Conference on Control \& Automation (MED), 25-28 June 2013, pp: 40 - 45.

[42] Azgomi, H.F. ; Poshtan, J , "Induction motor stator fault detection via fuzzy logic," 2013 21st Iranian Conference on Electrical Engineering (ICEE), 14-16 May 2013 pp: 1 - 5

[43] Pineda-Sanchez, M. ; Riera-Guasp, M. ; Antonino-Daviu, J.A ;"Diagnosis of Induction Motor Faults in the Fractional Fourier Domain," IEEE Trans on Instrumentation and Measurement, vol n ${ }^{\circ} 59$ ,pp: 2065 - 2075, Aug 2010.

[44] da Silva, A.M. ; Povinelli, R.J. ; Demerdash, N.A.O.,"Rotor Bar Fault Monitoring Method Based on Analysis of Air-Gap Torques of Induction Motor ," IEEE Trans on Industrial Informatics, vol $\mathrm{n}^{\circ}$ 9, pp: 2274-2283, Nov 2013.

[45] Zhang, X. ; Foo, G. ; Vilathgamuwa, M.D. ; Tseng, K.J. ; Bhangu, B.S ; Gajanayake, C.,"Sensor fault detection, isolation and system reconfiguration based on extended Kalman filter for induction motor drives," IET Electric Power Applications, vol n7,pp: 607 - 617, Aug. 2013.

[46] Teresa Orlowska-Kowalska, Piotr Sobanski,"Simple Sensorless Diagnosis Method for Open-Switch Faults in SVM-VSI-fed Induction Motor Drive," $39^{\text {th }}$ Annual Conference of the IEEE Industrial Electronics (IECON), November 2013 Vienna, Austria.

[47] El-Refaie, A.M.,"Fault-tolerant permanent magnet machines: a review," IET Electric Power Applications, vol n5 ,pp:59-74, January 2011

[48] B.Tabbache et al "PWM Inverter-Fed Induction Motor-Based Electrical Vehicles Fault-Tolerant Control," $39^{\text {th }}$ Annual Conference of the IEEE Industrial Electronics (IECON) , November 2013 Vienna, Austria.

[49] B.Tabbache et al "An improved fault-tolerant control scheme for PWM inverter-fed induction motor-based EVs," Elsevier ISA Transactions, vol 52, n6, pp: 862-869, November 2013

[50] D. Diallo, M.E.H. Benbouzid and M. Abul Masrur, "Guest editorial special section on condition monitoring and fault accommodation in electric and hybrid propulsion systems," IEEE Trans. Vehicular Technology, vol. 62, n³, pp. 962-064, March 2013. 